\title{
Por una Escuela Solidaria
}

Juan Miguel Batalloso Navas *

\section{Resumen}

La responsabilidad y la solidaridad como valores que alimentan los sentimientos de comunidad y fundamentan la ética (MORIN, E.; 2006: 25), así como las actitudes que se fundan en ellos, se adquieren y desarrollan mediante la experiencia y las prácticas sociales. A su vez y dado el escenario de crisis civilizatoria en el que estamos inmersos, la educación con y para la solidaridad y la responsabilidad se constituye en un imperativo moral de primer orden por lo que todas las instituciones educativas en general y las de Educación Básica y Obligatoria en particular deben asumir la responsabilidad social de educar en estos valores, aprovechando todas las posibilidades que brindan las mismas. Obviamente esto exige esfuerzos y compromisos multidimensionales, sostenibles y perdurables de carácter político, estructural, organizativo, curricular, educativo, docente y comunitario que pueden y deben estar dirigidos a construir y a desarrollar Escuelas Solidarias. Sin embargo esta aspiración que late y existe seminalmente en muchas de nuestras actuales escuelas, no podrá germinar y dar frutos si la solidaridad, la responsabilidad y la confianza no se constituyen como formas habituales, cotidianas y naturales de vida, trabajo, aprendizaje y convivencia. En esta línea, el presente artículo intenta aportar diversas reflexiones y sugerencias de carácter teórico y práctico basadas en las experiencias de su autor y orientadas a hacer posible la construcción y el desarrollo de una Escuela Solidaria.

Palabras clave: educación básica, solidaridad, responsabilidad, confianza, escuela.

\section{For a Solidarity School}

\begin{abstract}
Responsibility and solidarity as values that nurture feelings of community and based ethics (MORIN, 2006: 25), and the attitudes that are based on them, They are acquired and developed through experience and social practices. In turn and given the civilizational crisis scenario in which we are immersed, education with and for solidarity and responsibility becomes a moral imperative of the first order so all educational institutions in general and the Basic and Compulsory Education in particular They must take social responsibility to educate these values, using all the possibilities offered by them. Obviously this requires effort and commitment multidi-

\footnotetext{
* Doctor en Ciencias de la Educación - Universidad de Sevilla, España. Maestro de Educación Primaria. Miembro del Grupo de Investigación ECOTRANSD de la Universidad Católica de Brasilia. Miembro Del Consejo Académico Internacional de UNIVERSITAS NUEVA CIVILIZACIÓN. E-mail: batalloso@ gmail.com
} 
mensional, sustainable and enduring political, structural, organizational, curricular character, educational, teaching and community that can and should be directed to build and develop solidarity schools. However this aspiration that beats and exists in many seminally our schools today, you can not germinate and bear fruit if solidarity, responsibility and trust are not as common, everyday and natural lifestyles, work, learning and coexistence. In this line, this article attempts to provide various reflections and suggestions of theoretical and practical based on the experiences of the author and oriented to make possible the construction and development of a Solidarity School.

Keywords: basic education, solidarity, responsibility, trust, school.

\section{Introducción}

"Las virtudes no se originan en nosotros por naturaleza ni contra naturaleza, sino que lo hacen en nosotros que, de un lado, estamos capacitados naturalmente para recibirlas $y$, de otro, las perfeccionamos a través de la costumbre. Más aún: de cuanto se origina en nosotros por naturaleza primero recibimos las facultades y después ejercitamos sus actividades. Las virtudes, en cambio, las recibimos después de haberlas ejercitado primero. Lo mismo que, por lo demás, en las artes: los que hay que hacer después de aprenderlo eso lo aprendemos haciéndolo: por ejemplo los hombres se hacen constructores construyendo y citaristas tocando la citara. Pues bien, de esta manera nos hacemos justos realizando acciones justas y valientes. La virtud se origina como consecuencia y través de las mismas acciones.»

Aristóteles "Ética a Nicómaco"

Libro II.I. P. 76

La "Educación para la Solidaridad" en particular y lo que se conoce como "Educación en Valores" en general, son un área de conocimiento de las Ciencias de la Educación de antiguo recorrido en nuestras instituciones escolares y académicas. Bastaría con hacer un breve viaje por la Historia Pedagogía Social o por la Educación Moral, para darnos cuenta del extraordinario caudal de aportaciones, experiencias, modelos y teorías que aun a pesar del tiempo transcurrido y los cambios históricos acaecidos, siguen teniendo vigencia en muchas de sus propuestas y principios.

Desde el siglo XVII con las aportaciones de Juan Amós Comenio (1592-1671) con su ideal de educación para todos y sus propuestas didácticas para aprender por la experiencia combinando "devoción, instrucción y virtud", o desde los deberes cívicos e ideales humanitarios que la Escuela debe promover y realizar de Juan Bernardo Basedow (1723-1790), o también los principios de aprendizaje de Pestalozzi (1746-1827), basados en la actividad, la intuición, la autonomía y la creatividad, 
hasta llegar al siglo XX con las aportaciones Paul Natorp (1854-1924) el fundador de la Pedagogía Social, así como el movimiento educativo "Escuela Nueva" y de pedagogos como Georg Kerschenteiner (1854-1932), fundador de la Escuela del Trabajo dirigida a formar ciudadanos útiles para la sociedad, sin olvidar a John Dewey (1859-1952) con su énfasis en el aprendizaje por observación, por experiencia y en la participación social activa, las aportaciones se han venido sucediendo de forma constante. Así llegamos a mediados del siglo XX con la conocida "Educación Personalizada y Comunitaria" del jesuita Pierre Faure (1904-1988); el cooperativismo escolar, el aprendizaje por planes de trabajo, la asamblea de clase y el "Texto Libre" de Celestin Freinet (1896-1966), desembocando finalmente en los años sesenta con los principios y realizaciones de la "Pedagogía de los Pobres" o contra la pedagogía burguesa de Lorenzo Milani (1923-1967) y la "Pedagogía del Oprimido" y "Educación Liberadora" de Paulo Freire (1921-1997). Un recorrido enormemente fructífero que continúa desarrollándose y ampliando sus límites como podemos comprobar con las actuales aportaciones del movimiento social, educativo y pedagógico "Aprendizaje y Servicio” ya en pleno siglo XXI (BATLLE, R.; 2010 y 2013) (HERRERO, M.A. y TAPIA, M.N.; 2015) (PUIG, J.M.; 2007).

Básicamente, todas estas contribuciones vienen a dejar sentado que las instituciones educativas formales e informales en general y la Escuela Obligatoria tal y como la conocemos hoy en sus etapas de Infantil, Primaria y Secundaria, son organizaciones que cumplen una transcendental e importantísima función de socialización y aprendizaje de actitudes, valores y normas. La Escuela ha sido pues, y sigue siendo, una institución no solamente de aprendizaje instrumental, sino sobre todo un extraordinario agente de socialización, a pesar de que en la actualidad su influjo es mucho menor que en el pasado, dadas las transformaciones operadas en todas las instituciones sociales y especialmente en los agentes de socialización tradicionales.

No podemos perder nunca de vista que la educación es en sí misma un fenómeno y un proceso de naturaleza social, en cuanto que su tarea consiste en transmitir y renovar el patrimonio cultural producido por la misma sociedad. De hecho la educación escolar no es más que un proceso intencional y sistemáticamente planificado de socialización. A su vez, el objetivo fundamental de toda educación es promover la convivencia y la cohesión en torno a unos valores que se consideran deseables para esa sociedad, pero no de cualquier modo, sino mediante la creación de las máximas posibilidades de desarrollo personal y comunitario, teniendo en cuenta que dicho objetivo es inseparable de las garantías para el ejercicio de la ciudadanía democrática. De aquí podemos inferir que la promoción de valores democráticos, de convivencia pacífica, 
de cooperación y de solidaridad constituye una responsabilidad de primer orden de todas las instituciones educativas formales e informales.

Efectivamente y de acuerdo con lo señalado por el profesor Ortega Esteban, hoy día no es posible hacer una distinción entre educación escolar y educación social, lo mismo que tampoco podemos diferenciar entre educación escolar y educación comunitaria, sencillamente porque la Escuela como institución es en sí misma comunitaria, dado que trabaja comunitariamente y mediante los más diversos mecanismos de relación y vinculación social, al mismo tiempo que está integrada y responde a los intereses y finalidades sociales generales y específicas de la comunidad. (ORTEGA, J.; 2004).

Somos plenamente conscientes de que los escenarios de socialización, inculturación y transmisión de valores, no solo se han multiplicado de forma beneficiosa permitiendo acceder a numerosas fuentes de conocimiento y saber impensables hace tan solo unas décadas, si bien creemos que se trata de un beneficio paradójico y contradictorio, tanto por la pérdida de importancia e influjo de las funciones sociales de la Escuela, como por el gran esfuerzo supletorio y compensatorio que ésta tiene que hacer para desarrollar el pensamiento crítico y hacer posible la distinción entre información, conocimiento y sabiduría. Obviamente de esto se deriva que la educación y la responsabilidad social de educar y educarnos es un asunto que no compete en exclusiva a las escuelas, sino que compete a todos los ciudadanos y a todas las instituciones sociales, además de que es una tarea que hay que desarrollar a lo largo de toda la vida del individuo.

Afortunadamente hoy no existe ninguna escuela infantil, primaria, secundaria, o de enseñanza superior ya sea esta profesional o universitaria, que no tenga adoptada en las finalidades generales explicitadas en sus proyectos educativos el importantísimo y transcendental tema de la "Educación para la Solidaridad". Hoy son numerosísimas las instituciones educativas que realizan actividades, programas y proyectos de todo tipo dirigidos, tanto a crear conciencia de la necesidad de solidaridad y responsabilidad, como de otros valores éticos esenciales para nuestra convivencia y supervivencia.

En este sentido por ejemplo, el movimiento educativo internacional conocido como "Aprendizaje y Servicio" ha adquirido en todo el mundo un desarrollo extraordinario, especialmente en América Latina, haciendo posible combinar la adquisición y el desarrollo de competencias de aprendizaje con el servicio y la ayuda solidaria dirigida a satisfacer las necesidades de la comunidad local en que está enclavada la escuela, como a otras incluso muy distantes geográficamente. Consecuentemente y a pesar de 
que diariamente estamos sometidos e inmersos en numerosos conflictos sociales y políticos que dan testimonio de la capacidad humana para la crueldad y la injusticia, la Escuela y las instituciones educativas en general, siguen brindando una excelente oportunidad para construir espacios de solidaridad y abrir las puertas a la esperanza, de que más allá de todas las dificultades, es realmente posible construir un mundo más justo y más humano sembrando así semillas para una nueva civilización. (HERRERO, M.A. y TAPIA, M.N.; 2015).

Es obvio pues, que no hace falta justificar mucho la necesidad de "Educar para la Solidaridad", cuando vivimos en una civilización en permanente crisis económica, política, cultural y de valores atravesada por un feroz y depredatorio individualismo, en el que un tercio de la población malvive con menos de un dólar al día, o en el que se multiplican por doquier las desigualdades sociales. Sin embargo es necesario puntualizar y asumir de entrada, que de la misma manera que no podemos educar para la democracia sin aprender y hacer democracia, tampoco podremos educar para la solidaridad si no hacemos, practicamos, concretamos y visualizamos en nuestras conductas personales y organizativas cotidianas la solidaridad, por eso es mejor hablar de "Educación con y para la Solidaridad".

\section{El aprendizaje de la solidaridad}

Efectivamente, todas las escuelas e instituciones educativas siempre han tenido en mayor o en menor grado, alguna que otra actividad esporádica, conmemorativa e incluso sistemática y programada, dirigida a promover, animar, sensibilizar y hacer solidaridad aunque no se tenga muy claro lo que realmente significa este concepto. De hecho, la palabra y las actividades de solidaridad siempre aparecen en determinadas festividades, o también cuando un profesor o profesora movido por su conciencia personal y por los imperativos morales de su profesión, pone en marcha alguna que otra campaña de sensibilización que terminan muchas veces en acciones concretas de servicio a la comunidad.

En un sentido similar, aunque con un carácter más sistemático, pedagógico y justificado, dentro de lo que se ha conocido como "Áreas Transversales del Curriculum", son numerosos los programas, materiales y actividades que las diferentes administraciones escolares y las más diversas ONGs han elaborado y puesto a disposición de todas las escuelas para educar en la solidaridad. Verdaderamente, el atractivo, utilidad, profundidad y variedad de estos materiales, han alcanzado cotas de perfección inigualables que no podíamos hace unas décadas ni imaginar. Y es más, hoy gracias a 
la revolución del internet, nadie puede argumentar, ya sea docente, alumno, padre o madre, que no existan a su disposición casi infinitas actividades, programas y materiales para sensibilizar y educar en la solidaridad.

En consecuencia, cualquier institución educativa abierta a la creatividad, a la innovación y a la realidad social siempre incluirá en su proyecto educativo y curricular diversas actividades de "Educación en Valores" y de solidaridad, ya sean en forma de programas de Tutoría, de Orientación Educativa o de forma transversal en las diferentes áreas del curriculum. Y en todo caso, aunque no estuviesen explicitadas y formalizadas, esto es al menos lo que nos dice nuestra experiencia, siempre habrá algún profesor o profesora sensible y dispuesta a hacer todo lo que le sea posible, para que estos temas se desarrollen en el aula y el centro escolar.

Si bien es cierto que este tipo de prácticas docentes está cada vez más extendida y generalizada, es cierto también que existe una gran diversidad, tanto en la calidad como en la cantidad, frecuencia e intensidad de las mismas. Diversidad que depende como es obvio, de distintos factores, tales como el contexto social, el carácter del centro, las políticas y normativas curriculares y el compromiso personal de los docentes. Es pues bastante común, encontrar siempre en los documentos escolares y en los proyectos educativos declarados, objetivos y contenidos curriculares en los que se justifica su necesidad y se programan actividades concretas, dirigidas a trabajar educativamente, la solidaridad, la paz y no-violencia, la igualdad y la nodiscriminación o lo que se conoce como "Educación para el Desarrollo" o "Educación para la Ciudadanía”. En España por ejemplo, estos temas han sido preceptivos legalmente y han estado regulados y articulados curricularmente en las llamadas "Áreas Transversales", llegándose incluso a decretar la obligatoriedad de impartir una nueva materia escolar denominada "Educación para la Ciudadanía y los Derechos Humanos", una materia escolar por cierto, que originó mucho debate social y oposición por parte de las fuerzas políticas conservadoras que en cuanto llegaron al gobierno la eliminaron.

Es evidente pues que la gran mayoría de las escuelas e instituciones educativas de todo el mundo incluyen hoy en sus proyectos y programas, actividades de este tipo, en mayor o en menor grado, especialmente si se trata de escuelas primarias, pero a los efectos de este artículo, lo que nos interesa es preguntarnos acerca del impacto y la influencia que estos tipos de actividades tienen en la creación de actitudes personales solidarias en la ciudadanía.

En este punto, nuestra experiencia de casi cuarenta años como profesor de primaria, orientador escolar en secundaria y formador de profesores, aunque es obvia- 
mente limitada, nos dice que el impacto de todas estas actividades de "Educación en Valores" es realmente escaso. De cualquier manera, los factores que originan el que consideramos escaso impacto de este tipo de actividades son de diverso orden y aunque no podemos asegurar y generalizar nuestras apreciaciones, creemos que vale la pena reflexionar aunque sea muy brevemente sobre ellos.

Por una parte, nos encontramos con la naturaleza compleja de la educación y del aprendizaje, complejidad que además de impedirnos aislar variables supuestamente discretas como causas o factores determinantes exclusivos y únicos del aprendizaje, nos impide también considerar el mismo desde una sola dimensión o un único ámbito. Aunque sabemos gracias las aportaciones de Howard Gardner y su teoría de la Inteligencias Múltiples, (GARDNER, Howard ; 2001) que las capacidades humanas y/o "las inteligencias" no están uniforme y homogéneamente distribuidas en cada individuo, es cierto también que la cultura escolar que hemos conocido hasta ahora únicamente ha puesto el acento en el razonamiento verbal, el razonamiento numérico y parcialmente en el razonamiento abstracto, marginando en mayor o en menor medida los aprendizajes artísticos, creativos, interpersonales e intrapersonales, cuando son precisamente estos los que están en la base del aprendizaje de actitudes, valores y normas.

En este punto es necesario recordar que aprender y conocer no son capacidades consistentes en captar y almacenar información de la realidad considerada como algo externo a nosotros. Por el contrario, el conocer y el aprender, tienen una base biológica y son procesos permanentes que se construyen, reconstruyen y desarrollan a partir de las interacciones que una determinada estructura viva realiza con su medio ambiente, así como también de las interpretaciones y modificaciones que se producen en dicha estructura en el propio proceso de interacción. (MATURANA, H. y VARELA, F.; 1994).

Aprender y conocer no consisten pues en reproducir tal cual, lo que creemos procede de una realidad externa y objetiva que se nos es dada y que podemos fotocopiar y reproducir con exactitud a placer, ni mucho menos reproducir automáticamente una determinada conducta mediante modelamiento por imitación. Conocer y aprender no pueden por tanto reducirse a almacenar, reproducir o evocar información tal y como secularmente las instituciones escolares han creído siempre. No es pues ni un acto, ni un resultado siquiera, sino más bien un proceso de interacción entre un ser vivo caracterizado por una determinada estructura organizacional y funcional y el medio ambiente en que dicho ser vivo vive, convive y desarrolla sus procesos vitales.

Desde este punto de vista, el aprendizaje y el conocimiento humano se nos hacen procesos de una enorme complejidad. Tanto el ambiente como el propio ser 
humano están continuamente transformándose, interaccionando e interpretando y si a esto añadimos que nos relacionamos y socializamos mediante el lenguaje y que es éste el que configura y otorga sentido a la propia realidad social (BERGER, P. y LUCKMANN, Th.; 1984), necesariamente el aprendizaje siempre será algo singular, único y total en el sentido de que es el ser humano entero el que aprende y no una parte aislada del mismo. Por ello es evidente que no podemos reducir el aprendizaje humano a un puro mecanismo de almacenaje y evocación de información discreta y fija siempre pronta y dispuesta a ser reproducida y utilizada, como tampoco a un acto mecánico de imitación que mediante la repetición reiterada consigue determinadas modificaciones de la conducta.

A nuestro juicio, este reduccionismo puede conducirnos a tres importantes problemas. El primero, la imposibilidad de almacenar en nuestra mente escolarizada toda la información nueva que emerge y está a nuestra disposición, una imposibilidad que acaba por producir saturación, o la paradoja de estar desinformado como consecuencia de haber consumido demasiada información. El segundo la confusión entre información y conocimiento, que se expresa también de forma paradójica en el sentido de que no por el hecho de tener a nuestra disposición una abundantísima información, necesariamente vamos a producir un mayor y mejor conocimiento. Y el tercero, el problema de la especialización, que parcela, aísla, descontextualiza, niega la indisoluble relación sujeto-objeto y concibe el conocer como el acto de poseer muchísima información sobre algo muy pequeño y/o específico. En definitiva y a efectos educativos, puede entonces producirse en todos nuestros sistemas escolares, una gran contradicción: llegar a ser muy potentes y eficaces en suministrar información, procedimientos y habilidades para el acceso y el procesamiento de la misma, pero escasamente relevantes y significativos en proporcionar o ayudar a conseguir aprendizajes transcendentales e indispensables para nuestro vivir y convivir. Y esto traducido al ámbito de la "Educación en Valores" pone de manifiesto la clara insuficiencia de las metodologías exclusivamente cognitivas y discursivas.

\section{Dificultades para el aprendizaje de la solidaridad}

Las escuelas son instituciones altamente burocratizadas, reglamentadas y administradas, cuya rigidez, aunque sea producto de las normativas o de la costumbre, impide muchas veces hacer algo diferente o distinto a las actividades enmarcadas en las tradicionales disciplinas o en los libros de texto y guías de las empresas editoriales. Pero a su vez, las actividades relativas a la "Educación en Valores" se encuentran con el 
obstáculo insalvable del horario disciplinar. ¿Estas actividades deben hacerse permanentemente o solo en determinados momentos del calendario escolar? ¿Cómo fijar los tiempos en un horario reglamentado que no contempla la realización de estas actividades? ¿No perjudicarán al desarrollo de los contenidos de los programas escolares, de forma que les quite tiempo a los mismos y queden siempre temas por dar? ¿Estas actividades son realmente obligatorias o voluntarias? ¿Ocupan los tiempos necesarios o por el contrario ocupan un lugar marginal en el horario o el calendario escolar que justifica su escasa atención?

Hoy nuestras escuelas ya no son la prolongación de los hogares del mundo rural de antaño y muchísimo menos, aquellos reductos de estudio y contemplación para las clases privilegiadas y el clero. Hoy el formato es el de la gran industria, o el del shopping center, es decir, el de la concentración de grandes masas de operarios (profesorado) y usuarios (alumnado) cuya misión es consumir y consumir productos elaborados en los que ni operarios, ni consumidores intervienen. Incluso hasta las grandes administraciones educativas de los Estados se han transformado en el sentido de que ya no gozan de la autonomía y la independencia de hace unas décadas para diseñar y poner en marcha reformas educativas que pongan el acento en la identidad nacional, la cultura popular, las humanidades, la enseñanza profesional de base o la ética.

Hoy casi todo lo que se hace en nuestras escuelas se reduce a competir por conseguir un buen resultado en los rankings internacionales del Informe PISA (Programa Internacional para la Evaluación de Estudiantes) siguiendo así las orientaciones de la OCDE, que aunque sin duda alguna contienen elementos que es necesario tomar muy en consideración para diseñar políticas educativas estatales, lo cierto es, que en la práctica diaria y como consecuencia del impacto político, mediático y de las finalidades que este Informe persigue, posiblemente podamos llegar a la conclusión estereotipada y falaz de que lo único realmente útil y rentable que nuestros jóvenes deben aprender y desarrollar en su vida práctica (competencias) sea la lectura, las matemáticas y dosis variables de ciencia y tecnología.

Nuestras escuelas e instituciones educativas, se están transformando en espacios altamente competitivos e individualistas en los que lo único importante es obtener buenos resultados en exámenes y pruebas de todo tipo, centradas en aquellas habilidades operativas que son necesarias para la industria, el mercado y el más salvaje neoliberalismo. En consecuencia, si lo que se hace en nuestras escuelas es seguir unilateral y exclusivamente las orientaciones de este tipo de Informes, corremos el riesgo de que todas nuestras escuelas e instituciones educativas se conviertan en meros espacios en los que se adiestra a la infancia y a la juventud, en el manejo de habilidades y procedi- 
mientos cuya única utilidad viene justificada por el sacrosanto crecimiento económico que al parecer, es el único que produce desarrollo personal y social.

En la base de todas estas transformaciones, reformas curriculares e itinerarios de formación del profesorado, subyace a nuestro juicio el erróneo concepto de que todo crecimiento genera necesariamente desarrollo, cuando crecimiento y desarrollo humano son conceptos bien diferentes, como así está cansada de repetir la UNESCO y el PNUD. De este modo y transfiriendo esta falsa idea al terreno escolar, se terminará por concluir que todo lo que no sea habilidad lectora, matemática o tecnocientífica, no sólo no tiene valor, sino que además no es rentable. Atrás quedaran pues, todos aquellos conocimientos y programas de Ética o de Estética, de Historia o de Filosofía, de Artesanía o de Trabajos Manuales, de Psicología o de Sociología, de Autoconocimiento o de Creatividad, de Convivencia o de Cooperación, porque evidentemente estas áreas de conocimiento no son rentables ni productivas para las exigencias de la salvaje competitividad que el mercado globalizado y desregulado nos impone.

Todo encaja en la lógica neoliberal. La loca carrera de productividad y crecimiento sin límites, de competitividad, eficacia e incesante consumo, de sofisticación permanente de mercancías y deshumanización ha llegado hace tiempo a nuestras instituciones educativas. De una u otra manera nuestras escuelas están sometidas y subordinadas explícita e implícitamente al capitalismo, un modelo económico que ha dado ya sobradas muestras de poner en peligro nuestra propia supervivencia como especie. Por ello y desde esa lógica, las escuelas públicas no son rentables dado que los conocimientos y actitudes que se ofrecen en ellas no son relevantes para la productividad y el funcionamiento a gran escala del sistema social. No vale la pena pues enseñar y aprender actitudes éticas porque lo verdaderamente de interés es adquirir y desarrollar competencias que asuman como natural el actual (des)orden social establecido. Lo que interesa pues, es ampliar el mercado de la educación y dejarlo en manos de las grandes empresas educativas que institucionalizadas en academias particulares de entrenamiento para pasar exámenes, conviertan el complejo y humano arte de educar en una mera domesticación a base de premios y castigos, o de motivaciones extrínsecas para un futuro que cada vez es más incierto e imprevisible.

Nuestra experiencia nos dice, que este tipo de proyectos y actividades curriculares de educación para la solidaridad enmarcadas en lo que conocemos como "Áreas Transversales del Curriculum", al final, no solamente no tienen tiempo real para ser desarrolladas, sino que terminan finalmente por ocupar un lugar puramente testimonial. Y esto sucede así, porque el lenguaje educativo utilizado en los grandes discuros, declaraciones y leyes educativas no se ha correspondido con políticas activas y soste- 
nibles de formación, desarrollo profesional y dignificación del profesorado de educación básica, dejándolo permanentemente indefenso y desvalido ante la avalancha de responsabilidades, competencias y tareas que se la sociedad y los gobiernos de turno demanda a la Escuela. Todo queda pues en manos del heroísmo y la el voluntarismo individual de los docentes que más temprano que tarde originará en ellos situaciones de sufrimiento, quemamiento, abandono y llegado el caso de enfermedad.

Pero aun así, a pesar de todas las dificultades estas actividades sobreviven en las escuelas gracias al esfuerzo de anónimos héroes y heroínas de la educación, que encuentran sentido a su vida y a su profesión a partir de su sensibilidad, su conciencia solidaria y su convicción de que su trabajo es antes que nada una tarea de servicio y de responsabilidad social. Es obvio, que este tipo de actividades ya sean ocasionales o sistemáticas, deben seguir siendo desarrolladas de la forma más conveniente en nuestras escuelas. Es más, creemos con convicción que una Escuela Solidaria, debería estar centrada en sus programas, en torno a los valores éticos que sirven de fundamento a la Declaración de Derechos Humanos Universales y de desarrollo personal y comunitario, para a partir de ellos, desarrollar todas las competencias de aprendizaje asociadas a cada una de las disciplinas escolares. Claro que para esto, son insuficientes los programas papel-lápiz o las llamadas actividades de sensibilización consistentes en visionar y dialogar sobre situaciones de injusticia o de insolidaridad, dado que estos aprendizajes únicamente son perdurables y transformables en actitudes a través y por medio de la experiencia y la acción.

En definitiva, las dificultades para aprender solidaridad en nuestras escuelas, no solamente proceden de las concepciones mecanicistas que se tienen de los procesos de enseñanza y aprendizaje, o a la mayor o menor motivación y compromiso que tenga el profesorado para el desarrollo de proyectos y actividades de "Educación en Valores", sino que derivan sobre todo, de la naturaleza burocrática y la rigidez de las estructuras organizativas de las instituciones escolares y la subordinación de las mismas a fines y objetivos establecidos en políticas educativas exclusivamente centradas en el crecimiento económico y la competitividad.

\section{3. ¿Qué es una Escuela Solidaria?}

Una escuela o una institución educativa solidaria son algo muchísimo más profundo, orgánico y estructural que las episódicas actividades para sensibilizar y realizar ayudas asistenciales, y desde luego, muchísimo más vivo, existencial y cotidiano que el desarrollo de programas discursivos o de papel-lápiz producidos por pedagogos es- 
pecialistas en los que todo está convenientemente programado y articulado mediante actividades curriculares de carácter puramente cognitivo.

Si lo que normalmente se hace en las escuelas tiene a nuestro juicio un escaso impacto en la creación de actitudes y compromisos solidarios, así como en el desarrollo del pensamiento crítico, tal vez sea debido también a que no se tiene una comprensión suficiente del concepto de solidaridad y sus implicaciones prácticas, teóricas y educativas. La solidaridad no es ni puede reducirse a la ayuda caritativa, generosa y puntual que una determinada persona o colectivo social presta a otra o otros en situación de necesidad o desamparo, no solo porque este tipo de acciones son puntuales y muchas veces utilizadas como propaganda para otros fines, sino sencillamente porque coloca al dador de la ayuda en situación de superioridad generando en el receptor una situación de dependencia y legitimándolo como inferior e incapaz para salir de su situación. En correspondencia, tampoco podría decirse con propiedad que una institución educativa es auténticamente solidaria por el hecho de que esporádica o puntualmente destine determinados recursos y esfuerzos a programas de ayuda exterior, porque de lo que se trata no es solamente de realizar gestos de generosidad hacia afuera o hacia los que están lejos en las fechas y fiestas establecidas o en el tiempo en que el programa formativo se desarrolla en el aula. De lo que se trata es de aprender solidaridad desde dentro de la propia institución y desde dentro de las personas que integran la comunidad educativa y todo el conjunto de interacciones, relaciones y vínculos que establecen entre sí y con la comunidad local.

Una escuela solidaria es sin duda aquella que tiene que articular en sus programas educativos y en sus contenidos escolares, actividades dirigidas al aprendizaje de la solidaridad en todos los ámbitos del desarrollo personal y social, es decir, en las dimensiones cognitivas, afectivas, volitivas, sociales, éticas, políticas y espirituales, dimensiones que como es sabido, siempre funcionan integradas. Sin embargo, esto sería también insuficiente porque una Escuela Solidaria no es únicamente la que trata temas de solidaridad en sus programas, sino la que práctica la solidaridad en todas y cada una de sus estructuras, en todos y cada uno de sus espacios, en todas y cada una de sus interacciones y vinculaciones personales, afrontando al mismo tiempo el compromiso de aprender ofreciendo servicios concretos y útiles a la comunidad como es el caso de los proyectos educativos basados en el "Aprendizaje y Servicio".

La solidaridad no es ese sentimiento de conmoción o compasión que experimentamos cuando vemos a alguien que sufre o se duele. Este puede ser el comienzo de un proceso de aprendizaje solidario, pero por lo general este sentimiento termina por extinguirse cuando desaparece la percepción del hecho, o cuando movidos por 
la caridad, la generosidad, o el asistencialismo, hacemos un acto altruista, dirigido coyunturalmente a paliar el dolor o también a suavizar nuestro posible sentimiento de culpa. Pero además, la solidaridad tampoco es exclusivamente ese sentimiento de identidad y afiliación que se deriva de la pertenencia a un determinado grupo social o a una organización, aunque sean los grupos humanos los escenarios naturales en los que se expresa la solidaridad.

Así pues, todos estos programas dirigidos a que los alumnos se sensibilicen por las injusticias ajenas y lejanas, pueden representar indudablemente algo muy positivo para iniciarse en la solidaridad, pero no deben confundirse con la educación en, para y con la solidaridad. La solidaridad no se construye a partir de una situación de exterioridad, de lejanía o de superioridad. La solidaridad no es ni caridad, ni compasión, ni asistencialismo, lo que no quiere decir que no incluya bondad, generosidad y ayuda desinteresada. La solidaridad es algo mucho más profundo, intenso y permanente que no se restringe a un momento o a una acción concreta, sino que es más bien un proceso continuo de construcción cooperativa de igualdad en la diversidad.

En este punto, el maestro chileno Luis Razeto, nos lo deja bien claro cuando dice que «...la solidaridad es una relación horizontal entre personas que constituyen un grupo (1), una asociación o una comunidad, en la cual los participantes se encuentran en condiciones de igualdad (2). Tal relación o vínculo interpersonal se constituye como solidario en razón de la fuerza o intensidad de la cohesión mutua (3), que ha de ser mayor al simple reconocimiento de la común pertenencia a una colectividad. Se trata, en la solidaridad, de un vínculo especialmente comprometido, decidido, que permanece en el tiempo y que obliga a los individuos del colectivo que se dice solidario, a responder ante la sociedad y/o ante terceros, cada uno por el grupo, y al grupo por cada uno (4)..» (RAZETO, L.; 2005)

Partiendo de esta definición de solidaridad que nos ofrece el profesor Razeto, una Escuela Solidaria es al menos la que trabaja en función de cuatro grandes fines educativos y de desarrollo humano individual y comunitario:

1. Crear condiciones y garantías para que las relaciones entre las personas de la comunidad escolar sean horizontales, es decir, basadas en el reconocimiento mutuo, la confianza, la escucha activa, el diálogo, la tolerancia y la búsqueda de convergencias. Las relaciones horizontales o de confianza mutua no pueden darse de golpe, por impulsos o partiendo de prejuicios, estereotipos o narrativas previas acerca de cómo vemos a los demás y a nosotros mismos. Son en realidad el producto experiencias de reconocimien- 
to mutuo, acogimiento, cuidado, respeto y responsabilidad y su desarrollo depende del despliegue de afectos, cariño y en definitiva de sentimientos amorosos, así como de una percepción lo más clara posible de uno mismo y de los demás. (LANDAETA, F.; 2013).

2. Garantizar la igualdad de condiciones educativas y de desarrollo partiendo del reconocimiento de las particularidades de la diversidad de las personas, de forma que las diferencias individuales o de contextos escolares y sociales no se transforme en discriminaciones o en obstáculos insalvables para aquellas personas que presentan dificultades o determinadas carencias. En una Escuela Solidaria, es indispensable que las personas perciban y sientan que son tratadas digna y humanamente y no como objetos que deben ser manipulados o seducidos para cumplir u obedecer a determinadas tareas en base a normas externas o criterios puramente arbitrarios, selectivos y competitivos. En consecuencia una Escuela Solidaria no es la que trata, enseña, motiva, estimula o evalúa a todos por igual, sino aquella que compensa, ayuda, suplementa las posibles dificultades que las personas puedan presentar para el aprendizaje y su desarrollo, al mismo tiempo que construye permanentemente relaciones de cooperación.

3. Toda Escuela Solidaria, se va haciendo solidaria en la medida en que es capaz de crear relaciones de cohesión e integración comunitaria, desarrollando así una identidad propia y singular, abierta a la creación de una cultura escolar que la identifica y la dota de sentido estimulando el desarrollo de fuertes sentimientos de pertenencia. Las personas que trabajan y se comprometen en una Escuela Solidaria, la consideran y la valoran como un espacio físico, humano y social, de aprendizaje y de trabajo que las identifica, en el que se sienten reconocidas. Un espacio en suma en el que encuentran numerosas fuentes de participación, autorrealización, gratificación y protagonismo.

4. Finalmente y siguiendo al profesor Razeto, una Escuela Solidaria es aquella que desarrolla la responsabilidad en sus más diversos ámbitos: la responsabilidad personal e individual de profesores, directivos, familias y alumnado; la responsabilidad profesional de todos y cada uno de los docentes, gestores, administradores y personal laboral de la escuela; la responsabilidad colectiva de la Escuela como institución que tiene unos fines, objetivos y desarrolla unos programas educativos y formativos que aunque estén dirigidos al alumnado, no se reduce a ellos, sino que se amplían al profesorado 
y su perfeccionamiento como profesionales y a la propia ciudadanía de la comunidad local. Y una responsabilidad social entendida como respuesta solidaria a las necesidades tanto de sus miembros, de la propia institución, como de la comunidad local u otras comunidades en su caso.

Es evidente que la construcción, el crecimiento y el desarrollo de una escuela o una institución educativa solidaria no es algo que pueda surgir del vacío o de un punto cero inicial, sencillamente porque nada hay de nuevo que no haya emergido o no se haya basado o condicionado por lo viejo, pero también porque en las escuelas que conocemos hoy existen realmente abundantes semillas y realizaciones concretas fundadas en la cooperación, la colaboración y la solidaridad que deben ser aprovechadas, estimuladas y ampliadas.

Es de sentido común, que en una escuela que pretenda ser solidaria, no pueden rechazarse las actividades de sensibilización ante problemas e injusticias externas a la escuela, por el contrario, pueden y deben incluso promoverse con mayor intensidad y continuidad si cabe. Sin embargo, no es ésta su razón de ser, ni tampoco su metodología fundamental. En una escuela solidaria, los objetivos y actividades educativas no consisten en conmover, emocionar, apreciar, interpretar o ver la realidad desde una atalaya o un refugio puramente sentimental. En una escuela solidaria no es necesario predicar ni publicitar, sencillamente porque es la solidaridad misma, su práctica continua en todas las estructuras y actividades de la escuela la que la visibiliza.

La práctica de la solidaridad en las escuelas, obviamente afecta en primer lugar a la conducta y al compromiso de alumnos, profesores y familias, que necesariamente tiene que estar vinculado mediante la construcción colectiva de un proyecto educativo común construido y desarrollado colectivamente. Y esto exige de las escuelas una visión completamente diferente de la que actualmente tenemos.

Hoy concebimos las escuelas simplemente como lugares de estudio y aprendizaje a partir de libros, lectura, estudio, explicaciones de los profesores y por supuesto pruebas y exámenes que deben ser superadas para obtener acreditaciones. En este modelo, lo que opera es el esfuerzo individual con el fin de situarse en los lugares más altos de la selección, de las calificaciones. En una Escuela Solidaria, por el contrario, lo fundamental no es la infatigable lucha por los primeros puestos del ranking escolar, sino el esfuerzo por la extensión de la cooperación y la ayuda con el fin de que cada alumno en particular y con la singularidad de sus características, pueda adquirir las competencias básicas de aprendizaje establecidas o las metas que el propio grupo de 
alumnos o la escuela haya decidido. Para esto desde luego, no sería necesario hacer grandes cambios de infraestructura y recursos, sino sencillamente buscar sistemas y metodologías cooperativas y de responsabilidad compartida en las aulas, que pueden conocerse y aplicarse con facilidad. Pero aun así y pensando solamente en el alumnado, esto no sería suficiente.

Aplicar metodologías colaborativas y cooperativas en las aulas y en todos los organismos y dependencias de una escuela, algo por cierto que no está ni mucho menos generalizado en la actualidad, dado que en nuestras escuelas sigue primando el individualismo, es indudablemente una condición indispensable y básica, aunque también insuficiente. Una Escuela Solidaria, es por tanto la que hace, practica, trabaja, enseña, aprende y actúa con solidaridad, aunque también con responsabilidad. Una Escuela Solidaria es aquella que desde el primer momento del ingreso de los alumnos en sus instalaciones, ya sean únicas o repartidas en diversos espacios y establecimientos, hace posible que cada uno de ellos asuma una responsabilidad y un compromiso concreto de acción en favor de sus compañeros, de la comunidad escolar o de la comunidad local, siempre claro está, en función de las características y el nivel de desarrollo de cada uno.

Las escuelas solidarias, no son aquellas que dan todo hecho, preparado y cocinado de antemano a sus alumnos y profesores para que estos consuman y distribuyan conocimientos empaquetados curricularmente sin ofrecer nada a cambio de su propio esfuerzo y cosecha personal. No son pues escuelas de receptividad, de pasividad o de obediencia, sino escuelas de muchísima actividad en todos los órdenes, para cuya realización se requiere el concurso de todos y cada una de las personas que participan en ella, ya sean padres, madres, profesorado, directivos, agentes de la administración, alumnos o personas de la comunidad. Pero al decir de muchísima actividad, no estamos hablando exclusivamente de los procesos de aprendizaje que se desarrollan en las aulas, sino de todas las actividades y recursos que son necesarios poner en juego para que la escuela funcione. Las escuelas solidarias son pues y al mismo tiempo escuelas de responsabilidad.

Pongamos por ejemplo la necesidad del mantenimiento, el orden y la higiene de las aulas y determinadas instalaciones que pueden ser perfectamente asumidas por la totalidad del alumnado. O por ejemplo también, el trabajo inherente necesario para que determinados servicios como el comedor, la biblioteca, el gimnasio estén disponibles y funcionen cooperativa, solidaria y responsablemente. Son pues numerosísimas las posibilidades que un centro escolar brinda, para que familias, alumnado, profesorado y todos los profesionales que trabajan en el mismo, se responsabilicen y 
cooperen en un proyecto educativo que todos participan y construyen. La razón es obvia: si se desaprovechan estas oportunidades, estamos contribuyendo en mayor o en menor medida a la infantilización y a la dependencia, negando así las posibilidades de autonomía, creatividad y solidaridad. Por tanto, las escuelas solidarias son aquellas que combinan por lo menos cuatro tipo de trabajos o actividades: manuales, intelectuales, individuales y sociales. En gran medida se trata de escuelas autónomas y al mismo tiempo interdependientes, en las que se ofrece, se regala y se intercambia tiempo, talento, recursos, capacidades, inteligencia, creatividad, afectos, amistad y fraternidad. El modelo generalizado de escuela infantilizada y ortopédica que hemos creado, es un modelo que ha propiciado en gran medida la incapacidad y la inutilidad para muchas de nuestras capacidades creativas y posibilidades de desarrollo humano, entre ellas por ejemplo nuestras potencialidades y habilidades para el trabajo manual y productivo. Las escuelas primarias, secundarias y terciarias de hoy, no son lugares para el trabajo manual, artesanal, técnico con resultados económicos, productivos y de servicio, sino que por el contrario, son por lo general instituciones para promover casi en exclusiva habilidades mentales y/o cognitivas de carácter puramente individual. Con razón decían nuestros padres que debíamos estudiar para liberarnos de la esclavitud del trabajo físico y manual, porque en el pasado siglo y en el actual, trabajar con las manos es algo muy poco valorado y remunerado socialmente. Sin embargo hoy podemos constatar que aquella vieja movilidad social que propiciaba la escuela en el pasado siglo a los alumnos más aventajados en la selección, está desapareciendo si no lo ha hecho ya. Caminamos y vivimos en sociedades con tasas elevadas de desempleo permanente, que en muchos países alcanzan cifras de extraordinaria gravedad, o en sociedades de empleo precario y "mini jobs" en las que prolifera y se instaura también de forma permanente, la economía informal y popular. Despreciar pues las posibilidades que una escuela puede aprovechar para autogestionarse, autoabastecerse e incluso contribuyendo al sostenimiento de sí misma y de la comunidad, es completamente absurdo.

Pero además de esta realidad, es evidente que no hay ningún trabajo físico que no requiera la integración de determinados grados de aprendizaje cognitivo, emocional y social.

¿Puede una escuela, ya sea primaria, secundaria o terciaria contribuir a la autogestión de las necesidades económicas de la comunidad? Sin duda alguna, y esto es algo que puede constatarse en numerosas experiencias que se están desarrollando en este instante en muchos países gracias a las experiencias y proyectos de "Aprendizaje y Servicio". ¿Por qué no puede tener cada escuela, por ejemplo, un espacio agrícola 
y ganadero o un huerto que no sirva solamente para hacer experimentos, sino para producir bajo las condiciones técnicas más adecuadas? Obviamente se nos dirá, que en las ciudades no hay espacios naturales para los huertos, pero hoy son también numerosas las experiencias que mediante huertos urbanos se contribuye en mayor o en menor medida al autoabastecimiento. Pero en cualquier caso, una Escuela Solidaria no es exactamente una escuela agrícola, aunque puede serlo, sino la que crea condiciones para que el trabajo manual, artesanal con carácter económico y a pequeña escala, pueda ser desarrollado. Con este carácter, la eterna división entre trabajo manual e intelectual que tanto el mercado como los sistemas educativos han contribuido a crear, no solo tendería a difuminarse sino que además, al centrarse dichas actividades en procesos solidarios, es decir de corresponsabilidad, cooperación, confianza y colaboración, estaríamos contribuyendo también a disolver y suavizar la eterna división entre pensantes y ejecutantes, dirigentes y dirigidos, hombre y mujer, etc.

No es ninguna utopía que una escuela pueda desarrollar al mismo tiempo un trabajo de aprendizaje, un trabajo de cooperación para el mantenimiento de la comunidad y un trabajo artesanal, productivo o de servicio comunitario. Son numerosas las experiencias que se están desarrollando en todo el mundo en este sentido. (GONÇALVES, V.; 2010) (TRUJILLO, F y ARIZA, M.; 2010) (HERRERO, M. A. y TAPIA, M.N.; 2015)(MEC; 2015)

Otro aspecto de fundamental importancia de toda Escuela Solidaria, es la singularidad y las particularidades de la misma escuela. Si la solidaridad es un proceso que se construye a partir de la cooperación, la corresponsabilidad, la creatividad y la autonomía, las escuelas solidarias necesariamente tendrán que ser diversas y singulares. En ellas no cabe la estandarización a la que estamos acostumbrados con el modelo burocrático estatalizado que normaliza y reglamenta exhaustivamente lo que debe o no debe hacerse en las escuelas. Por ello, no necesariamente cada escuela tiene que adoptar la forma de un centro productivo a pequeña escala, sino que será cada comunidad la que determine, cuáles son los ámbitos posibles y necesarios de cooperación y en los que fraguar el compromiso solidario. Así por ejemplo, existen también numerosas experiencias de cooperativismo escolar, en las que la comunidad, el profesorado y el alumnado se corresponsabilizan del funcionamiento y el mantenimiento de determinados servicios que se realizan en las escuelas tales como comedores, bibliotecas, actividades complementarias y otros.

Una Escuela Solidaria, no puede ser por tanto una escuela pasiva, receptiva y consumidora de recursos y servicios. Por el contrario y si quiere ser realmente solidaria, tendrá que compartir y poner en marcha proyectos, iniciativas, programas y 
actividades desde dentro de la misma comunidad escolar, en las que la cooperación, la colaboración y las responsabilidades libremente asumidas y compartidas sean el medio y el fin que den sentido a todas sus finalidades educativas, sin perder nunca de vista, que al mismo tiempo debe cumplir con las funciones de aprendizaje que tradicionalmente le son propias.

Así pues, una Escuela Solidaria es aquella que está atravesada y practica en su vida cotidiana la solidaridad en todas sus dimensiones: en los contenidos escolares, en las aulas, en los patios de recreo, en el profesorado, con los padres y madres de familia, con la comunidad, en los órganos de gestión y organización del centro, en sus estructuras económicas de gestión y administración, en sus procedimientos y mecanismos de perfeccionamiento y desarrollo profesional, así como en sus criterios y herramientas de evaluación.

¿Cómo podríamos evaluar entonces el grado de solidaridad de una escuela? ¿Podrían establecerse algunos criterios básicos?

En primer lugar, el nivel de solidaridad de una escuela puede valorarse en función del grado de profundidad, intensidad, frecuencia y solidez de las relaciones sociales y los vínculos cooperativos y afectivos que en ella se establecen. Una escuela que funciona como un shopping, movida por rutinas o por un activismo esporádico y supuestamente innovador producto de modas y tendencias mercantiles y en el que profesores, padres y alumnos se comportan como extraños en la cola de un supermercado, o como adversarios eternos en los que prima la desconfianza, no podrá ser nunca una escuela solidaria. Por el contrario, una escuela que se compromete con las personas, que las respeta, que las considera en los saberes originales que cada una posee y aporta y que promueve el encuentro, el diálogo, la confianza y la amistad tiene evidentemente muchas posibilidades de convertirse en una Escuela Solidaria. Dicho de forma sucinta: una Escuela Solidaria es aquella que promueve y practica relaciones de confianza y cooperación sólidas, es decir, ni líquidas, ni gaseosas.

A su vez, una Escuela Solidaria es aquella que promueve y practica relaciones de igualdad y de reconocimiento mutuo de saberes. Una escuela que pretenda ser solidaria no puede rechazar, ni mucho menos despreciar los saberes populares, los saberes del trabajo manual, los saberes del buen vivir y del sentido común que han contribuido a que generaciones enteras vivan y sobrevivan sin necesidad de estar escolarizadas. Una Escuela Solidaria por tanto, es aquella que valora y reconoce la dignidad esencial de cada persona, al mismo tiempo que estimula el desarrollo de todas y cada una de las capacidades y habilidades de cada uno de los miembros de la comunidad escolar. Una Escuela Solidaria, no puede ser aquella que cree que el único que sabe, puede y debe 
enseñar es el maestro, sino por el contrario, aquella otra que busca, investiga, reconoce y da oportunidades de cooperación a los diferentes maestros y maestras de humanidad, de profesionalidad o de artesanía que existen en la comunidad. Una Escuela Solidaria, es aquella que borra y hace posible la eliminación de los límites y las fronteras entre lo escolar y lo extra-escolar, aprovechando el inmenso caudal de posibilidades culturales, de aprendizaje y de saberes acumulados que tiene la comunidad y que la escolarización por lo general ha despreciado siempre.

Por último, una Escuela Solidaria es la que además de hacer solidaridad, es decir, centrarse en las necesidades y en los problemas concretos y específicos de la propia escuela, de la comunidad, de las aulas y de las personas individualmente consideradas, promueve y hace también democracia directa y no meras liturgias representacionales dictadas por las burocracias. Democracia directa, que consiste en una acción continua de participación, colaboración y cooperación en un proyecto social y educativo constituido por la propia escuela en sí, proyecto que al ser participado, sentido y realizado como propio, hace posible también la cohesión y la solidez necesaria, que va mucho más allá de la simple pertenencia identitaria, para dar lugar así, a la práctica de la solidaridad permanente. Una Escuela Solidaria es la que hace posible el desarrollo de valores y actitudes democráticas, como consecuencia y efecto de la práctica continua de la libertad y la responsabilidad.

Finalmente, no nos resistimos a traer aquí la letra de una canción, que desde el primer año en el que tuvimos la oportunidad de ejercer como maestro de escuela en 1973, en plena dictadura franquista, nos ha acompañado siempre como himno emblemático de que otra escuela y otro mundo son realmente posibles. Se trata de la canción "Simplemente solidario" compuesta y cantada por el cantautor, folclorista y antropólogo chileno Valericio Leppe (1937-2004) que acompañado de la voz y la guitarra de Eladio López, constituían en 1971 el Dúo Coiron, que formaba parte de todo aquel movimiento musical llamado " $\mathrm{La}$ nueva canción chilena". Aquella canción, que tan sentimentales recuerdos nos trae como consecuencia de haberla enseñado y cantado muchísimas veces con nuestros alumnos decía así:

«Simplemente solidario, conducta de amanecer, carajo hermano que cuesta al Ego poder vencer.

Deme la mano y la tomaré, que si va solo se pue perder, pa hacer la yunta, pa hacer la yunta, no basta un buey.

Simplemente solidario, debemos mostrar la luz, 
para sacar de la sombra, al enemigo común.

Deme la mano y la tomaré...

Necesario es distinguir, la acción de los solidarios,

para dar su medicina, al enfermo y al sectario.

Deme la mano y la tomaré...

Una escuela solidaria, la tendremos verá usted, formaremos manos buenas, solidarias para el bien.

Deme la mano y la tomaré...

Compañero si resbalas, cien manos te ayudarán, solidario simplemente esta tierra sembrará.

Deme la mano y la tomaré... »

Sirva pues este artículo también, para rendir homenaje a aquellos cantores chilenos que plantaron las semillas de valores eternos de los que hoy estamos sumamente necesitados.

\section{El papel del Profesorado}

Aun imaginando que nada de lo que hemos sugerido hasta ahora fuese posible y que en nuestras aulas tuviésemos suficientes actividades basadas en metodologías participativas y cooperativas. ¿Sería bastante con ello? Pues tampoco, porque nos olvidaríamos de las condiciones laborales, profesionales y materiales en las que viven las profesoras y profesores de infantil, primaria y secundaria, que son a nuestro juicio los auténticos sembradores de valores.

El modelo funcionarial vigente en la enseñanza pública, que tan bien ha protegido a sus trabajadores con la seguridad de un empleo para siempre y no pocos privilegios consuetudinarios, al menos en Europa, aunque ahora reciban fuertes agresiones en sus condiciones laborales como consecuencia de la crisis, ha generado también patologías y excrecencias funcionales. Individualismo, abstencionismo, indolencia, corporativismo y diversas conductas no catalogables, son algo que forma parte de la diversidad del paisaje de las burocracias escolares.

El hecho de que los profesores se conviertan exclusivamente en funcionarios docentes especializados y no en profesionales de la educación al servicio de la comunidad, genera culturas laborales claramente individualistas, balcanizadas, meritocráticas y orientadas por lo general al ascenso o a la necesidad de ocupar puestos en las jerarquías de las administraciones educativas de mayor prestigio y salario, al mismo 
tiempo que de menor esfuerzo y trabajo individual. Es decir, generan culturas laborales basadas en el beneficio individual, que conducen además al individualismo y al corporativismo más ramplón que incluso es interno y visible, tanto en los diferentes niveles y estructura del sistema educativo como en escuelas, mediante las diversas diferenciaciones de estatus y salarios. Así pues, por muchas actividades curriculares de solidaridad que se realicen en las escuelas, si el profesorado no trabaja en equipo, no comparte sus materiales y experiencias, no asume responsabilidades en el colectivo, no se reúne y coopera en la realización de proyectos educativos comunitarios, o no puede trabajar desde la horizontalidad o sencillamente no asume la necesidad de promover y realizar actividades y proyectos solidarios, la construcción de una Escuela Solidaria no pasará de ser un romántico sueño irrealizable.

A su vez, si la estructura organizativa de la escuela está reglamentada de tal modo que no hay espacio para la autonomía profesional y para la creatividad, es evidente que será muy difícil también hacer solidaridad en la escuela. Y en el ámbito de la gestión y de la organización escolar, si los directivos de los centros escolares, no son auténticos testimonios y modelos de solidaridad capaces de estimular, asesorar y liderar procesos de innovación y cooperación educativa, pedagógica, docente y comunitaria, difícilmente también podremos conseguir en la práctica una Escuela Solidaria.

Si la dirección de los centros escolares está sometida exclusivamente a los dictados de la estructura de mandarinato de la burocracia escolar. O si el directivo, que es muy frecuentemente un hombre en una comunidad docente constituida en su mayoría por mujeres, las posibilidades de construir escuelas solidarias y superadoras de la discriminación por razón de género, serán evidentemente menores y no digamos si estas posibilidades chocan con las diversas formas de autoritarismo y desclasamiento que muchas veces estos funcionarios adoptan. No puede por tanto entenderse una Escuela Solidaria que no esté autogestionada y basada en la más amplia participación de padres, madres, profesores, gestores, alumnos y agentes de la comunidad. No puede concebirse una escuela verdaderamente solidaria que haga solidaridad y no solamente la predique con discursos o con respuestas puntuales a necesidades ajenas y distantes, si esa escuela no es profundamente democrática en todos sus ámbitos, es decir, si no es al mismo transparente, participativa, reflexiva y autocrítica, o si no asume la necesidad y el principio democrático de poder elegir a aquellas personas que pueden y son aceptadas plenamente para dirigir y hacer posible el desarrollo un proyecto educativo que es compartido y autogestionado por toda la comunidad.

No cabe ninguna duda de que el papel del profesorado, de los directivos y de los 
gestores escolares resulta de una transcendental importancia puesto que sin su concurso, su participación, su compromiso personal y profesional no sería posible desarrollar un proyecto educativo solidario e iniciar el camino para la construcción de una Escuela Solidaria. No obstante, para ello es sumamente necesario y urgente abordar medidas y reformas de política educativa de gran calado dirigidas especialmente a garantizar que el trabajo docente en la Escuela Obligatoria deje de ser lo que ha venido siendo hasta ahora, tanto en el sentido de la mejora material de las condiciones laborales y profesionales de las maestras y maestros de escuela, como en el de los cambios cualitativos de carácter organizativo y formativo.

No puede aceptarse por otra parte, que convivamos con problemas cada vez de mayor complejidad y dificultad para ser resueltos y no seamos capaces de ayudar a concebir y a repensar la realidad de otra manera diferente. No podemos seguir hablando de que vivimos en un mundo complejo, si no proporcionamos los aportes de formación necesarios para que el profesorado cambie sus enfoques, sus marcos de visión conceptual y sus actitudes para hacer frente a sus funciones y competencias. $Y$ en este cambio conceptual y actitudinal, ya no bastan tampoco los tratados y especulaciones abstractas y eruditas, sino la acción concreta que se evalúa y mejora permanentemente a través de la reflexión colectiva y las ilustraciones que proceden de las ciencias y las humanidades. El profesorado necesita, más que mayores y mejores tecnologías, que ya las tiene a su disposición, nuevas formas de entender los fenómenos educativos, nuevas formas de comprender el desarrollo humano y nuevas formas de asociarse y cooperar superando el ancestral individualismo.

Los problemas de una escuela en general y la construcción de una Escuela Solidaria en particular, ya no son exclusivamente el problema de un determinado alumno, de un determinado profesor o de una sola escuela. Los problemas y necesidades de un centro escolar no pueden ser ya considerados como enfermedades individuales que una vez identificadas, puede aplicarse a ellas coyunturales recetas terapéuticas salvadoras. Los problemas de las escuelas, aunque se presenten individualmente, tienen rasgos y orígenes comunes, impactan colectiva y comunitariamente, y dada su complejidad no pueden ser abordados individualmente. Ya no basta con que en una escuela haya buenas maestras y maestros que educan lo mejor que pueden a los alumnos de su aula. Ya no es suficiente con recurrir al valor, al coraje, a la valentía o a la vocación del profesorado de enseñanza básica, sobre todo cuando sabemos que estas cualidades han sido siempre utilizadas por los administradores y gestores de la educación para someterlos a políticas educativas discriminatorias que han naturalizado mediante el chantaje del voluntarismo y el heroísmo, la imposibilidad de mejorar las condiciones 
laborales, profesionales, formativas y de dignidad de las maestras y maestros de Educación Obligatoria.

Necesariamente hay que dar un salto hacia el trabajo en equipo, dialogado, coordinado, cooperativo, porque este es el más enriquecedor camino para atender a la diversidad y hacer frente a la complejidad. Nadie tiene ya la varita mágica de la metodología didáctica universal que resuelva de inmediato los problemas, por ello las escuelas, tendrán que orientarse hacia su transformación en "Centros de Aprendizaje y Desarrollo Comunitario", más que en "Centros de Enseñanza" expedidores de títulos y credenciales como sucede ahora.

Pero esta transformación organizativa y estructural, que es sobre todo y ante todo de naturaleza política, (POSTAY, V.; 2002), exige también de una transformación actitudinal, o si se prefiere de una nueva orientación ética y autoformativa de la función docente (DAY, C.; 2005 y 2012). Un docente o un profesor que trabaja en la enseñanza básica, es muchísimo más que un funcionario que cumple normativas o que un trabajador injustamente tratado que exige legítimas reivindicaciones a las que tiene derecho. La maestra o el maestro de la Escuela Solidaria del siglo XXI, es sobre todo un trabajador de lo humano, un servidor de las personas, un profesional cuya ética personal y profesional le exige asumir la responsabilidad social de la función educadora, que siempre está más allá de la letra de la ley o de las normas de las burocracias escolares.

La función docente, el trabajo de maestro de escuela, no es entonces un trabajo exclusivamente técnico, de autorrealización, artístico, etc. es sobre todo un trabajo de responsabilidad social y política, que emerge y se sostiene tanto a partir de las condiciones materiales de existencia personal y profesional en el que el maestro vive, como de las convicciones y actitudes éticas que motivan su conducta. Pero la ética personal y profesional de las maestras y maestros de escuelas, no son solamente principios y normas aprendidas en los libros y tratados morales, proceden de sus experiencias vitales y profesionales, de la interpretación y comprensión que tiene de las mismas y del sentido particular que le da a su profesión. (BATALLOSO, J.M.; 2014).

Pero si el trabajo de educador, se nutre de experiencias y actitudes éticas, de uno u otro modo, las maestras y maestros de escuela están llamados a la construcción de sentido y por tanto a la construcción de fuentes de energía que alimenten ese sentido y esas funciones. Y esas fuentes de energía, entendemos que hay que encontrarlas a partir del sentimiento de autocompetencia y del desarrollo de la autoestima personal y profesional, así como del placer de convivir, el gozo de ayudar, la alegría de aprender, la pasión por el conocimiento, el gusto por la cultura, las experiencias artísticas, la dación y recepción de cariño y afecto, la contemplación de la belleza, la fresca sorpresa de 
nuevas situaciones, el vivir el presente a cada instante, el valor de rebelarse y desobedecer y otras muchas que hacen referencia a lo que puede entenderse como desarrollo emocional y espiritual en el sentido de que la educación es realmente un fenómeno de naturaleza solidaria y amorosa. (MORAES, M.C.; 2003).

La formación inicial y permanente, así como el desarrollo profesional del profesorado de enseñanza básica, creemos que debería primar aquellas experiencias y saberes que permitiesen la construcción de sentido y la alegría agradecida de ejercer una maravillosa profesión llamada siempre a servir a la infancia y a la juventud. La formación del profesorado debe proporcionar recursos y estrategias para que los profesores principiantes y experimentados encuentren motivaciones intrínsecas en su trabajo o sentido vocacional y de autorrealización a su profesión, y esto exige a nuestro juicio abordar contenidos y actividades de desarrollo personal y espiritual que son los que constituyen la base, el fermento y la energía de todas las competencias docentes y de todos los sentimientos de autorrealización. No podemos pedir al profesorado que eduque para la solidaridad o la responsabilidad cuando él mismo está siendo tratado por las administraciones educativas y por la sociedad de un modo insolidario, injusto e irresponsable.

No podemos exigir al profesorado que contagie alegría, entusiasmo o esperanza, cuándo él mismo es un ser triste, decepcionado, derrotado, marginado, discriminado y maltratado en sus condiciones laborales y materiales de existencia. Por ello las maestras y maestros de una Escuela Solidaria para el siglo XXI, necesitan hoy más que nunca considerar que sus problemas, necesidades y los compromisos personales y profesionales que se derivan de los imperativos morales de su función social, son problemas de naturaleza política que requieren con urgencia de medidas políticas estructurales y sostenidas de dignificación, formación y desarrollo profesional. Y es que muy a menudo se olvida consciente o inconscientemente, que las profesoras y profesores de enseñanza básica son personas y profesionales con una enorme responsabilidad que ya no puede mantenerse a base de heroísmo y mediante normas alejadas de la realidad cotidiana en la que viven y afrontan complejísimos y difíciles problemas que agotan su capacidad de resistencia.

Pero nada está perdido. Las escuelas de hoy, de las que conocemos todas sus insuficiencias, sus funciones sociales y mecanismos de reproducción y legitimación ideológica, siguen a nuestro juicio ofreciendo muchas posibilidades que permiten en términos puramente prácticos y cotidianos recuperar viejas actividades enormemente útiles y crear ambientes más cooperativos y solidarios. En realidad una Escuela Solidaria no es ningún proyecto formalizado y fabricado por especialistas o por funcionarios 
de la administración escolar, sino más bien un proceso permanente de convivencia, colaboración y cooperación cotidiana que se construye momento a momento, que está sujeto a vaivenes así como a avances y retrocesos.

Se trata de un proceso que se alimenta de acciones educativas, que a veces pueden parecer insignificantes, pero que tienen una enorme importancia a la hora de interiorizar y hacer normal conductas de confianza, responsabilidad y colaboración. Todo aquello que en una escuela se haga para evitar el individualismo, la competitividad y el éxito académico a cualquier precio, por muy pequeño o poco importante que nos parezca, estará contribuyendo a sembrar semillas para la creación de una cultura de colaboración y cooperación, cultura que es sin duda una de las bases del ejercicio de la solidaridad. Y para la creación de esta cultura, no hay nada más útil, práctico y productivo que la convivencia, el trabajo y todo tipo de relaciones y vinculaciones basadas en la confianza. Dicho en otras palabras: no podemos aprender a ser solidarios y a desarrollar comportamientos y actitudes de solidaridad, si no somos capaces de aprender a confiar y a expresar conductas de confianza.

\section{La confianza como base y alimento de la solidaridad}

Confiar es básicamente mostrar que tenemos esperanza y fe en los demás, estar inequívocamente seguros de que las relaciones que mantenemos son sanas, gratuitas y responsables. La confianza no es un trato, no es un convenio para mercadear sobre ganancias y pérdidas, es sobre todo una actitud interior que nos lleva a plantear y realizar conductas sanas, honestas y sinceras, sin dobleces ni expectativas, sin mentiras y sobre todo sin venganzas disfrazadas de buenos modales o de conductas contaminadas de hipocresía, soberbia y vanidad. Es a través de la confianza como aprendemos a practicar la comprensión humana percibiendo y sintiendo que somos seres complejos, erráticos y llenos de contradicciones y que como dice el mensaje evangélico, no podemos nunca tirar la primera piedra porque estamos llenos de defectos, prejuicios, racionalizaciones y autojustificaciones.

Sin confianza es imposible mantener ningún tipo de relación social, ya sea económica o política, ciudadana o educativa, profesional o personal. Confiar es también la actitud que nos permite leer en positivo la realidad, siendo capaces de reconocer nuestras distorsiones cognitivas que motivadas por el miedo, el egocentrismo o las falsas expectativas nos hacen sentirnos inseguros y bloqueados frente a los retos de nuestra vida. 
La confianza, como cualquier otra actitud, posee tres tipos de elementos integrados que son de naturaleza cognitiva, emocional y volitiva. Exige conocimiento y por tanto de atención y observación para poder discernir y permitirnos las dosis de seguridad necesarias para hacer frente a las situaciones. Y exige de conocimiento también, para que nos proporcione seguridad, de que lo que hacemos o nos hacen, sirve para nuestro desarrollo y es para nuestro bien, en el sentido de que lo que se nos presenta es fruto de la voluntad de hacer las cosas bien. De aquí la importancia del esfuerzo acompañado del placer y la conciencia de alcanzar un máximo ideal de perfección.

El desarrollo de la confianza exige pues así un doble trabajo de aprendizaje: de un lado un esfuerzo deliberado por investigar, cuestionar, pensar críticamente o discernir en suma; y de otro un esfuerzo consciente por dar lo mejor de nosotros mismos en aquellas tareas que realizamos, algo por cierto a lo que la escuela actual viene prestando cada vez menor atención. El placer por la tarea bien hecha, el sentimiento de autocompetencia que se experimenta haciendo aquello en lo que creemos y que mejor se adecua a nuestras posibilidades, el cultivo de la paciencia, de la mediatización de los deseos, del cuidado por el detalle, la tolerancia a la frustración, etc, son elementos esenciales que contribuyen a desarrollar tanto la confianza en nosotros mismos, como la confianza en los demás.

A su vez, la confianza posee igualmente, elementos emocionales que se activan a partir de actitudes de acogida, de calidez afectiva, de horizontalidad, de sencillez, de humildad y sobre todo de empatía. No puede entenderse el aprendizaje de la confianza sin el aprendizaje de la empatía, sin ese saber comprender al otro situándonos en su punto de vista y en su situación. Por ello el aprendizaje de la confianza no puede darse mediante el miedo, siempre generador de hostilidad, desencuentro, antipatía o también desde el prejuicio y los estereotipos que aceptamos sin más, por no haberlos pasado por la criba del discernimiento.

Emocionalmente también, la confianza se aprende a partir de lo que podría denominarse como un "dejarse llevar", como una especie de abandono ante la actitud de generosidad y buena voluntad del que nos escucha, acoge y nos nutre, permitiéndonos así eliminar tensiones, estrés y cualquier tipo de ansiedad. No en vano, las primeras personas generadoras y productoras de confianza son los padres y especialmente las madres, cuando acogen, acunan, abrazan y acarician a sus hijos que "se abandonan" a un estado de tranquilidad, serenidad y relajación, en el que ya la seguridad, no es sólo producto de lo puramente conocido, sino de la vivencia de un presente nutritivo de afecto y amor incondicional. De aquí, el extraordinario e importantísimo papel que 
juegan los procesos de dar y recibir afectos en el aprendizaje y el desarrollo tanto de la confianza, como de la solidaridad.

Pero a su vez, la confianza se nutre de decisiones, de actos, conductas, hechos, porque a la postre, son siempre las acciones las que muestran, clarifican y hacen visible la confianza, aportando la necesaria credibilidad y coherencia tanto de nuestra propia conducta como de la conducta ajena. Son pues los hechos, nuestras decisiones, nuestros actos los que proporcionan el soporte, la base, o el pedestal al partir del cual la confianza se aprende integrándose con nuestros procesos cognitivos y emocionales.

Podría decirse incluso, que la confianza es la actitud o el valor que está en la base del aprendizaje multidimensional y retro-prospectivo en el sentido de que exige una triple visión o percepción. Necesita de observación y atención para discernir, permitiéndonos así conducir nuestra vida mediante la información que nos aportan los datos e imágenes que nos ofrecen los demás como espejos de nuestras propias acciones, así como también la información que que nos brindan nuestros propios espejos retrovisores, ya sean laterales o traseros. Necesita igualmente de sensibilidad presente y en el instante, o si se prefiere de atención sensible al flujo que nace en la comunicación verbal y no verbal, siendo capaz de dar y recibir afectos, siendo capaz en suma de agradecer y de acoger con esmero lo que recibimos prestando atención a los sentimientos y emociones que emergen y que es necesario expresar y en su caso, modular realizando los movimientos pertinentes para que la conducción de nuestra vida y de nuestras relaciones sociales sea suave, placentera y exenta de tirones, frenazos y brusquedades, que son precisamente las iniciadoras de la desconfianza. Y necesita finalmente de visión de futuro, de amplias perspectivas de visión de horizonte, de ser capaces de llevar nuestro propio volante de forma relajada, sin tensiones, lo cual comporta la aparición tres elementos nuevos esenciales que aparecen en su aprendizaje: la fe, la esperanza y el compromiso.

La confianza ya sea como actitud individual o como característica que funda y sostiene lo organizativo, institucional y/o colectivo exige necesariamente verdad, transparencia, claridad, sinceridad, honestidad, ausencia de manipulación, empatía, sensibilidad, afecto, ternura y todo un conjunto de valores éticos que están más incluidos y conectados con la ética del cuidado de la cultura matríztica y planetaria-ecoespiritual, que con la ética de la justicia y la imparcialidad. (MATURANA, H. y VERDEN ZÖLLER, G.; 2003: 43 y 45) (HATHAWAY, M. y BOFF, L.; 2014).

La confianza no puede surgir y desarrollarse sin la presencia permanente, viva y actuante de la ética del cuidado y de la ética de la justicia, que son las que garantizan al mismo tiempo la vida y la igualdad esencial de todos los seres humanos junto a la protección de sus derechos universales. Por ello la confianza, ya sea individual-inter- 
personal o colectiva-institucional, nunca podrá surgir, construirse, reconstruirse o desarrollarse en suma, si ignoramos las condiciones materiales, contextuales e históricas de partida en las que convivimos en el presente. La confianza exige reconocimiento legítimo del otro (individual o colectivo) al mismo tiempo que memoria histórica (espejos retrovisores), es decir, conocimiento, reconocimiento, reparación, dignificación de los excluidos, oprimidos y víctimas olvidadas por la historia, por las instituciones o por las burocracias. $\mathrm{Y}$ es aquí donde reside, además de que la solidaridad se aprende haciendo solidaridad, la transcendental importancia de que toda Escuela Solidaria tenga necesariamente que implicarse en proyectos sociales, en acciones concretas dirigidas a servir a todos los miembros y necesidades de la Escuela, como a la comunidad local y social en general.

La creación de relaciones de confianza no es posible si no somos capaces de realizar análisis retro-prospectivos y acciones concretas de reconocimiento del otro, acciones que necesariamente tienen que estar fundadas en los valores de la ética del cuidado, como ternura, afecto, tolerancia, generosidad o perdón, entre otros. Por ello no se trata de realizar actos de arrepentimiento separados de la acción, sino de reconocer abiertamente sin subterfugios los errores de nuestra conducta pasada que provocaron la desconfianza y apostar sin miedo por la realización de aquellas acciones individuales y colectivas que abran nuevas posibilidades presentes y futuras de confianza.

Vivir y crear relaciones de confianza es algo consustancial para construir y mantener espacios de solidaridad, para construir, mantener y desarrollar una Escuela Solidaria y desde luego también para el ejercicio y el desarrollo de una convivencia pacífica y democrática, para lo cual no basta una buena voluntad abstracta o meramente conceptual o sensiblera, ni mucho menos el olvido del pasado. La confianza como actitud individual y colectiva de apuesta y fe en el ser humano, no puede emerger y desarrollarse sin el reconocimiento y la memoria de la injusticia, una memoria que no es un camino de revancha, venganza o victimismo, sino de reconciliación, reconocimiento y de reparación de todo aquello que se puede reparar.

Cuando hoy escuchamos con frecuencia, el descarnado discurso de políticos, empresrios y banqueros sin escrúpulos que nos repiten y justifican diariamente sin cesar, que la condena a la pobreza de pueblos enteros es debida a lo que llaman "falta de confianza de los mercados", estamos sin duda ante la perversión más injusta y cruel de lo que aquí estamos planteando como aprendizaje de la confianza. Por ello, la confianza, no es bajo ningún concepto el olvido, ni la expectativa de ganancia, ni tampoco el recurso para conservar privilegios, o supuestas condiciones ventajosas para ambas partes. No obstante, la confianza tiene también una dimensión colectiva, que es al 
mismo tiempo, social, cultural, económica y política que se nutre evidentemente de la ética del cuidado, la justicia y la solidaridad.

Analizada la confianza como el constituyente que sostiene y nutre de energía a grupos, organizaciones e instituciones, no cabe duda de que su función va mucho más allá del reconocimiento del hecho social. Es a través de la confianza como los individuos que interactúan y se comprometen en grupos y organizaciones sociales contribuyen al ejercicio de las funciones y la consecución de los fines y objetivos de las mismas. Pero es también por medio de la confianza, como se establecen relaciones de interdependecia y cooperación mutua entre las diferentes instituciones y sociedades, permitiendo así reducir la incertidumbre al apostar por expectativas de beneficio mutuo que excluyen el miedo como componente que bloquea e inhibe las relaciones.

La confianza no es sólo pues, un rasgo o actitud de la conducta individual, sino también de las relaciones entre grupos, organizaciones, sociedades y estados, un aspecto que cobra una transcendental importancia en el plano económico y en el político. La desconfianza está en el origen de la codicia, la ganancia, el abuso de poder, el autoritarismo o el puro teatro representacional de las democracias de mercado de nuestro tiempo; la manipulación; la ausencia de interiorización de valores democráticos; la exigencia de delegación de cada vez mayores espacios de participación; la relaciones de mando/obediencia; la presencia permanente de violencia, guerra y conflictos bélicos; el poderío simbólico y mediático de la industria de la conciencia; el pensamiento único que ciega, bloquea y deslegitima continuamente las posibilidades de transformación social, así como toda la variada gama de conductas organizativas (locales y globales) basadas en la dominación, la conquista, el chantaje y en la escandalosa e injusta distribución de la riqueza, tienen su base en la desconfianza y en el miedo. En una desconfianza que hunde sus raíces en la cultura del patriarcado que promueve y legitima la ambición, la jerarquización, la agresión, la violencia, el autoritarismo y la exclusión de las mujeres.

Pero hay algo más acerca de la confianza como fenómeno humano que caracteriza a las relaciones interpersonales, grupales e institucionales y que está en la base de unas relaciones sociales sanas, sostenibles y solidarias, así como en la construcción de una equilibrada y auténtica imagen de nosotros mismos. Y es que la confianza tiene también una dimensión transcendente y expansiva. La confianza como dice Maturana, no es sólo el valor que constituye lo social, sino que es también el fundamento de la misma vida, porque es a través y por medio de la confianza como se abren nuevos espacios y dimensiones de relación y vinculación; es gracias a la confianza como podemos expresar, hacer visibles y compartir nuestras emociones; es por la confianza como 
conseguimos crear nuevas posibilidades de ayuda mutua e interdependencia; es gracias a la confianza en suma, como podemos vivir/convivir. La confianza en definitiva es el sostén, el nutriente básico, la energía que hace surgir y promueve la solidaridad y el amor.

La desconfianza, no es pues lo natural, sino lo culturalmente aprendido mediante la mentira, la codicia, la corrupción, la explotación, la competitividad y las variadas formas de dominación, degradación y perversión que unos seres humanos ejercen sobre otros y sobre la propia naturaleza. Consecuentemente, crear y construir relaciones de confianza, es algo mucho más profundo y expansivo que el aprendizaje del trueque o el intercambio entre iguales, o eso que eufemísticamente llaman ahora "cultura emprendedora" que es más bien la cultura de la ganancia y la rentabilidad, porque la confianza, al ser un constitutivo del vivir/convivir es la que permite actualizar, refrescar y alimentar el amor como fenómeno biológico y humano. (MORAES, M.C.; 2003).

\section{Más allá de la confianza y la solidaridad}

$\mathrm{Al}$ ser la confianza la que mejor sostiene la convivencia y en última instancia la solidaridad y el amor, la confianza llevada a su máximo desarrollo se transforma en fe, una fe que es fuente permanente y transcendente de inspiración y de vida. Una fe que es la manifestación o la expresión de una confianza básica implícita, a priori, incondicional, (ALMAAS, A.H.; 2002: 18-25) que se funda en la convicción de que todo lo que sucede, es lo mejor que puede suceder, dado que todo está conectado, vinculado y religado complejamente en infinitas redes y flujos de materia, energía e información que no podemos controlar. Una fe basada en la humilde convicción de que «...el conocimiento es navegar en un océano de incertidumbres a través de archipiélagos de certezas...» (MORIN, E.; 1999: 47), pero una fe caracterizada también por la ausencia de expectativas, el desapego a los resultados, en la conciencia de que todo es caminar y caminar. Una confianza en suma, que al hacerse fe y echar raíces en nuestro interior, nos transforma alimentándonos de una especie de conformidad existencial no conformista, ni indolente, sino enactiva y energética, creativa y transcendente que llega a comprender que «todo es para el bien» como nos decía Sor Juliana de Norwich y que por tanto nada hay que perder ni que ganar, sino solamente agradecer y agradecer la posibilidad de que con nuestro esfuerzo podemos cambiar el mundo y a nosotros mismos. 
Por todo esto, aprender a confiar a partir del reconocimiento de nuestros semejantes como legítimos e iguales a nosotros, así como aprender a trabajar la confianza como principio activo que genera sinergias de cooperación, ayuda mutua y solidaridad, es una de las tareas más importantes para la creación y el desarrollo de una Escuela Solidaria. No obstante, para iniciar el camino de la confianza es necesario tomar plena conciencia de cuáles son los factores que están en el origen de la desconfianza en nuestras relaciones interpersonales. En este sentido y siguiendo a Frank Petermann, la desconfianza se origina como consecuencia de al menos tres tipos de conductas. La ausencia y/o destrucción de la comunicación; como efecto de la elección y manifestación de acciones amenazantes y por una ruptura intencional de la confianza acompañada de acciones de deslegitimación del otro (PETERMANN, F.; 1999). Por tanto, para aprender vivir y crear relaciones de confianza, necesariamente tenemos que trabajar simultáneamente tanto la comunicación, como la comprensión humana.

¿Qué podemos hacer entonces para vivir y crear relaciones de confianza en nuestras escuelas? ¿Qué principios o criterios debemos adoptar para crear ambientes de confianza o condiciones que permitan hacerla emerger y desarrollarla? ¿Qué habría que tener en cuenta a efectos educativos, para construir, desarrollar y sostener la confianza en todas sus dimensiones? ¿Cómo cultivar la confianza interpersonal, la organizativa y esa confianza básica regeneradora y creadora de permanentes posibilidades de desarrollo personal?

Es obvio que no hay recetas universales porque cada persona en particular es un singular y complejo ser marcado por su biografía, condicionado por su ego y en permanente interacción con su contexto medioambiental que es cambiante y también singular. Pretender inventariar un catálogo de fórmulas para aprender a confiar o a comprender humanamente a los demás, como si fuese posible establecer un camino certero y exacto para la creación de confianza y comprensión es una tarea, además de enormemente complicada, inútil. Con la confianza, sucede algo parecido a lo que ocurre con la virtud como decía Aristóteles o con la paz en el sentido en que Gandhi afirmaba al decir que "no hay un camino que lleve a la paz, la paz es el camino", es decir, en ello funciona una especie de "ley del karma" en el sentido de que si siembras confianza y comprensión, obtendrás con toda probabilidad confianza y comprensión, o viceversa: si tu conducta es de incomprensión y desconfianza pues necesariamente obtendrás desconfianza e incomprensión.

La sugerencias que proponemos pues, no son más que observaciones personales, producto de nuestra particular manera de ver las cosas que como es obvio res- 
ponden a nuestras singulares experiencias y a aquellas lecturas que nos han permitido sistematizar e interpretar de alguna manera lo vivido.

Hechas estas salvedades, para vivir y crear relaciones de confianza en nuestras escuelas y poder así convertirlas, mantenerlas y desarrollarlas como Escuelas Solidarias habría que tener en cuenta al menos los siguientes elementos de reflexión:

1. Aprender a aceptar nuestra vulnerabilidad y nuestra condición humana de seres contingentes y complejamente configurados como sapiens-demens, prosaicus-poethicus, faber-ludens, economicus-ethicus, estheticus-transcendentales.

2. Asumir el miedo como un componente de nuestra estructura psicobiosociológica que nos ayuda a la prevención, la precaución y el cuidado, al mismo tiempo que nos plantea retos de superación, esfuerzo y trabajo consciente, no para superarlo, sino para aceptarlo como componente, que no debe en ningún caso entorpecer nuestras relaciones, nuestros proyectos y nuestra peregrinación existencial de seres en camino.

3. Aprender a escuchar, a acoger, a empatizar y sobre todo a comunicarnos horizontalmente partiendo de esa confianza básica que proporciona el reconocimiento de que el otro es un igual a mí y que me puede enseñar, ayudar y comprender de una forma original y recíproca.

4. Dar y recibir afectos de una forma completamente incondicional: regalar una mirada, una sonrisa, un “ibuenos días!" lleno de cordialidad y simpatía. Aprender a desdramatizar, despresionar, destensar procurando establecer climas de atención, serenidad y sosiego en los que el otro perciba realmente que se siente escuchado y acogido.

5. Desarrollar todas las formas de sensibilidad humana posibles, desde las más físicas y sensoriales, hasta las más psíquicas y sentimentales, comprendiendo que cada ser humano es en realidad un micromundo complejo imprevisible que no puede reducirse a datos, ni biológicos, ni psicológicos, ni biográficos siquiera.

6. Promocionar estados sutiles de reflexión y emoción en los que podamos comprender que la fe es la luz que alumbra siempre la posibilidad de cambio y transformación y que por tanto la esperanza es el elemento más trascendental y transversal de cualquier ser humano. 


\section{Referências}

AA.VV. Escuela y Comunidad: la propuesta pedagógica del aprendizaje servicio. Actas del $3^{\circ}$ y $4^{\circ}$ Seminario Internacional "Escuela y Comunidad". [En línea] <http://bit. ly/1RklRO5> [Consulta: 25 marzo 2016]

ALMAAS, A. H. Facetas de la unidad. El eneagrama de las ideas santas. La liebre de marzo: Barcelona, 2002.

ARISTÓTELES. Ética a Nicómaco. Alianza: Madrid, 2001.

BATALLOSO NAVAS, J. M. La profesión de profesor en el siglo XXI. Universitas Nueva Civilización: Santiago de Chile, 2014.

BATLLE SUÑER, R. Aprendizaje Servicio (APS): educación y compromiso cívico. Graó: Barceolona,2010.

BATLLE SUÑER, R. El Aprendizaje Servicio en España: el contagio de una revolución pedagógica necesaria. PPC: Madrid, 2013.

BOFF, L. Ética e eco-espiritualidade. Verus: Campinas SP, 2003.

CRESPI, F. Aprender a existir. Nuevos fundamentos de la solidaridad social. Alianza: Madrid, 1996.

DAY, C. y GU, Qing. Profesores: vidas nuevas, verdades antiguas. Una influencia decisiva en la vida de los alumnos. Narcea: Madrid, 2012.

DAY, C. Formar docentes. Cómo, cuándo y en qué condiciones aprende el profesorado. Narcea: Madrid, 2006

GARDNER, H. La inteligencia reformulada. Las inteligencias múltiples en el siglo XXI. Paidós: Barcelona, 2001.

GONÇALVES GARDIM, V. O ensino da agrecologia sob um regime de alternância: a Escola Técnica Milton Santos do MST. Universidade Estadual de Londrina. 
Londrina (Paraná-Brasil). 2010. [En línea] < http://bit.ly/1SrSsR6 > [Consulta: 28 marzo 2016].

HATHAWAY, M. y BOFF, L. El Tao de la liberación. Una ecología de la transformación. Trotta: Barcelona, 2014.

HERRERO, M. A. y TAPIA, M. N. (comp.). III JORNADAS DE INVESTIGADORES SOBRE APRENDIZAJE Y SERVICIO CLAYSS. Centro Latinoamericano de Aprendizaje y Servicio Solidari. Buenos Aires. 2015. [En línea] <http://www.clayss.org/3jornada/Libro_IIIJIA-S.pdf> [Consulta: 26 marzo 2016)

LANDAETA FARIZO, F. Relaciones horizontales. Revista "Somos". Santiago de Chile. 2013. [En línea] <https://www.revistasomos.cl/2013/06/relaciones-horizontales/> [Consulta: 27 marzo 2016]

MATURANA R. H. y DÁVILA Y. X. Habitar humano. Palas Athena: Sao Paulo, 2009.

MATURANA R. H. El sentido de lo humano. Dolmen: Santiago de Chile, 1996.

MATURANA, H. y VARELA, F. De máquinas y seres vivos. Autopoiesis: La organización de lo vivo. Universitaria: Santiago de Chile, 1994.

MATURANA, H. y VERDEN-ZÖLLER, Gerda. Amor y juego. Fundamentos olvidados de lo humano. J.C. Sáez: Santiago de Chile, 2003.

MECD. Escuelas de éxito. Características y experiencias. XII Encuentro de Consejos Escolares Autonómicos y del Estado. Secretaría General Técnica. Madrid. 2015. [En línea] <http://bit.ly/22UtOgV> [Consulta: 28 marzo 2016]

MONTES, R.; TAPIA, M. R. y YABER, L. Manual para docentes y estudiantes solidarios. Natura-CLAYSS. Buenos Aires. 2011. [En línea] <http://bit.ly/1RALR3F> [Consulta: 25 marzo 2016]

MORAES, M. C. Educar na biologia do amor e da solidariedade. Vozes: Petrópolis RJ, 2003. 
MORIN, E. Los siete saberes necesarios a la educación de futuro. Paidós: Barcelona, 2001.

MORIN, E. El Método 6. La ética. Cátedra: Madrid, 2006.

ORTEGA ESTEBAN, J. Pedagogía social, realidades actuales y perspectivas de futuro. XIX Seminario Internacional de Pedagogía Social. Santiago de Chile. 2004. [En línea]< http://bit.ly/1Rwxoqi> [Consulta: 22 marzo 2016]

PETERMANN, F. Psicología de la confianza. Herder: Barcelona, 1999.

POSTAY, V. Las escuelas solidarias del modelo neo-neo y la formación de la cultura política: el caso del Programa Nacional de Escuela y Comunidad. Cuadernos de Educación. Universidad de Córdoba. 2002. [En línea] <http://bit.ly/1qbwVmL $>$ [Consulta: 28 marzo 2016]

PUIG ROVIRA, J. M. Aprendizaje Servicio. Octaedro: Barcelona, 2007.

RAZETO MIGLIARO, L. El concepto “Solidaridad”. Pensamiento Crítico Latinoamericano. Conceptos Fundamentales, Volumen III, págs. 971-985. Ediciones Universidad Católica Silva Henriquez. Santiago de Chiles. 2005. [En línea] <http://www.uvirtual. net/spuv/node/110> [Consulta: 26 marzo 2016]

TRUJILLO S., F. y ARIZA P. M. A. (ed.) Experiencias educativas en aprendizaje cooperativo. 2010. [En línea] <http://bit.ly/1Uq4qOS> [Consulta: 28 marzo 2016]

Recebido em: 29 março 2016.

Aceito em: 06 abril 2016. 